\title{
A Democracia Como Direito Social, o Coto Vedado e a Tutela da Participação Efetiva no Processo Democrático
}

\section{Democracy As Social Rights, the Coto Vedado and Safeguarding of Effective Participation in the Democratic Process}

\section{TIAGO SETTI XAVIER DA CRUZ}

Graduado em Ciências Jurídicas e Sociais pela UPF - Universidade de Passo Fundo/RS, Pós-Graduado (Lato Sensu) em Direito Constitucional pela Ulbra - Universidade Luterana do Brasil/RS, Mestre em Direito pelo Centro Universitário Toledo - Unitoledo/SP, Membro do Conpedi - Conselho Nacional de Pós-Graduação em Direito e da SBPC - Sociedade Brasileira para o Progresso da Ciência, Professor da Graduação (Direito Processual Civil) no Centro de Ensino Superior de Jataí - CESUT (GO), Advogado. Autor de obra e de artigos científicos publicados.

Submissão: 17.04 .2012

Decisão Editorial: 28.06.2012

RESUMO: A partir da compreensão do surgimento do Estado Moderno, é possível estabelecer parâmetros claros relativamente ao constitucionalismo, movimento que inicialmente adveio justamente como forma de estabelecer limites ao poder estatal em face do indivíduo, e, como consequência, permitir que a forma de governo republicana, legitimada pela democracia, pudesse ser estabelecida. Nesse sentido, utilizando-se do método hipotético-dedutivo, o trabalho percorre as etapas sucessivamente atingidas pelo Estado Moderno, desde sua forma liberal até o formato de Estado Democrático Constitucional, traçando pontos de intersecção com o constitucionalismo. Em um segundo momento, 0 trabalho aborda as teorias de democracia majoritária e de consensual, cujos modelos inspiram análises particularizadas para a compreensão da legitimidade do poder exercido pelo Estado sobre os indivíduos. A par dos elementos informativos já trazidos, na terceira seção é examinada a teoria do coto vedado, como forma de limitação implícita ao poder de reforma constitucional que implique prejuízos ao próprio regime democrático. Ainda, o estudo examina a tutela jurisdicional da participação efetiva no processo democrático, por meio da ADPF, com vistas à concretização do direito fundamental à democracia participativa.

PALAVRAS-CHAVE: Estado moderno; constitucionalismo; democracia; reforma constitucional; tutela jurisdicional; efetividade.

ABSTRACT: From the understanding of the emergence of the modern state can establish clear benchmarks for constitutionalism, a movement that sprang originally just as a way of setting limits to state power in the face of the individual, and as a consequence, allow the republican form of government, legitimized by democracy could be established. In this sense, using the hypothetical-deductive method, the work goes through the successive stages reached by the modern state, from its shape to 
the shape of liberal Democratic Constitutional State, plotting points of intersection with constitutionalism. Secondly, the paper discusses the theories of majoritarian democracy and consensus, which models inspire particularized analysis for understanding the legitimacy of power exercised by the state over individuals. A couple of pieces of information have brought in the third section we examine the theory of forbidden stump, by way of limitation the implied power of constitutional reform that implies damage to the democratic regime itself. And yet, the study examines the legal protection of effective participation in the democratic process, through the ADPF, with a view to achieving the fundamental right to participatory democracy.

KEYWORDS: Modern state; constitutionalism; democracy; constitutional reform; judicial protection; effectiveness.

SUMÁRIO: Introdução; 10 Estado Moderno e o constitucionalismo; 2 As teorias de democracia majoritária e consensual; 2.10 modelo majoritário de democracia; 2.20 modelo consensual de democracia; 3 A democracia participativa direta como direito social; $4 \mathrm{~A}$ teoria do coto vedado; $5 \mathrm{~A}$ tutela da participação efetiva no processo democrático; Conclusão; Referências.

\section{INTRODUÇ̃̃OO}

O fenômeno político ${ }^{1}$, vinculado à tradição clássica das civitas, à realização do "Homem na Sociedade" e ao bem comum temporal, na visão de Jorge Miranda (2005, p. 01-02), apresenta-se por meio do fato da vida do homem e dos valores que impregnam a visão realística da sociedade. Liga-se, ainda, a elementos como, por exemplo, as condições de legitimidade dos governantes para a realização de reformas constitucionais que tratem de direitos fundamentais.

Na atualidade, a análise do fenômeno político mostra-se relevante para a teoria do Estado, justamente em face da verificação das condições de legitimidade governamental, esboçada nas diferentes exteriorizações do processo democrático.

Nesse ínterim, a democracia aqui é vista como a conjunção de cinco critérios a que um processo para o governo de uma associação teria de corresponder, que, nas palavras de Robert Dahl (2001, p. 49-50), são:

Participação efetiva. Todos os membros devem ter oportunidades iguais e efetivas para fazer os outros membros conhecerem suas opiniões sobre qual deveria ser a política a ser adotada pela associação.

Igualdade de voto. Quando chegar o momento em que a decisão sobre a política for tomada, todos os membros devem ter oportunidades iguais e efetivas de voto e todos os votos devem ser contados como iguais.

Entendimento esclarecido. Dentro de limites razoáveis de tempo, cada membro deve ter oportunidades iguais e efetivas de aprender sobre as políticas alternativas e suas prováveis consequências.

1 O fenômeno político pode ser entendido como "a atividade ou conjunto de atividades que, de alguma maneira, têm como termo de referência a pólis, ou seja, o Estado" (Bobbio, 2004, p. 954). 
Controle do programa de planejamento. Os membros devem ter a oportunidade exclusiva para decidir como e, se preferirem, quais as questões que devem ser colocadas no planejamento. O processo democrático exigido pelos três critérios anteriores jamais é encerrado. As políticas da associação estão sempre abertas para a mudança pelos membros, se assim estes escolherem.

Inclusão dos adultos. Todos ou a maioria dos adultos residentes permanentes deveriam ter o pleno direito de cidadãos implícito no primeiro dos critérios. (grifos do autor)

Não é nada simples encontrar a melhor maneira de interpretar os padrões democráticos, aplicá-los a uma associação específica - no caso o Estado, cujo conceito será oferecido logo adiante - e criar as práticas e as instituições políticas que eles exigiriam. As opções exigirão incontáveis julgamentos teóricos e opiniões práticas, com dificuldades como, por exemplo, provável conflito entre os critérios acima referidos por Robert Dahl, tendo que se ponderarem valores conflitantes.

A partir de uma breve análise da evolução do Estado e sobre o constitucionalismo, o trabalho abordará a teoria da democracia, sob enfoque conceitual-crítico, levando ainda à verificação de se e como seria possível caracterizar a democracia como um direito social - não apenas de primeira dimensão/geração, mas para além disso.

Como consequência, este artigo ainda tem por objetivo compreender como o sistema de legitimação da teoria do coto vedado se estabeleceu dogmaticamente. A compreensão desses institutos e fenômenos permitirá, em um momento final, a abordagem da efetividade do direito à participação democrática por via da tutela jurisdicional.

Os objetivos do trabalho, sua problemática, justificativa e hipóteses resumem-se, pois, nas averiguações acima brevemente referidas, sendo que o método de pesquisa utilizado foi hipotético-dedutivo, que tradicionalmente é definido como um conjunto de proposições particulares contidas em verdades universais. Entretanto, para que os argumentos científicos sejam testados, é necessário comprovar sua refutabilidade.

Esse método também pode ser chamado de crítico ou da tentativa e erro, sendo descrito por Popper (1974, p. 45) no início do século. Apresentado o problema, o investigador lança uma hipótese para explicá-lo. Depois, deduzem-se da hipótese os testes com potencial para refutá-la. Se o resultado dos testes refutar a hipótese, ela é eliminada. Se o resultado dos testes não refutar a hipótese, ela é suportada ou corroborada.

Daí que uma definição simplista do método hipotético-dedutivo pode ser endossada como sendo aquele que vai do conhecimento geral para o particular, sem trabalhar com verdades, mas apenas com etapas de possibilidades, cujas hipóteses são comprovadas ou excluídas. 
O método de procedimento deste artigo foi o de pesquisa bibliográfica. Esse procedimento de pesquisa é reflexivo sistemático, controlado e crítico, desenvolvido a partir de material já elaborado, constituído principalmente de livros e artigos científicos, obras de divulgação que proporcionam conhecimentos científicos sobre o tema ora proposto.

\section{ESTADO MODERNO E O CONSTITUCIONALISMO}

Norberto Bobbio (2004, p. 425) assinala que o Estado Pré-Moderno não é um conceito universal, mas apresenta-se com a função de descrever uma forma de ordenamento político

surgida na Europa a partir do século XIII até os fins do século XVIII ou inícios do XIX, na base de pressupostos e motivos específicos da história europeia e que após esse período se estendeu - libertando-se de certa maneira, das suas condições originais e concretas de nascimento - a todo o mundo civilizado.

Essa definição histórico-crítica do Estado Pré-Moderno tem sentido desde o momento em que a nova forma de organização política chamada de Estado Moderno se caracteriza pela "progressiva centralização do poder segundo uma instância sempre mais ampla, que termina por compreender o âmbito completo das relações políticas" (Bobbio, 2004, p. 426), somada ao princípio da territorialidade e da evolução da impessoalidade do comando político.

Max Weber (2004, p. 522-523) assinala que o caráter da centralização do poder político representa o "monopólio da força legítima". Isso permite a ilação de que a centralização é antagônica ao policentrismo feudal que ocorria até então, o que tornou o Estado funcional e organizado.

Nesse momento [Estado Pré-Moderno ou propriamente Moderno²] é que a organização política medieval - policêntrica - acaba por ruir, já que a ampla série de autoridades com jurisdição própria, verticalmente dispostas, precisa dar espaço para a noção de Estado, em sua plena acepção. Com o poder concentrado no governo e, por conseguinte, toda a autoridade pública sob sua emanação, sua força atinge a todos os governados, nos limites do território.

Jorge Miranda (2005, p. 32) explicita que o surgimento desse novo modelo foi acompanhado de uma crescente institucionalização, quando, ao seu ver, Luís XIV disse que "O Estado sou eu" não no sentido de personalização ou

2 Para Lênio Streck e José Luis Bolzan de Morais (2004, p. 24-29), a questão do surgimento do Estado dito "Moderno" gera dúvidas e críticas, inclusive citando Norberto Bobbio (Estado, governo, sociedade: para uma teoria geral da política. Rio de Janeiro: Paz e Terra, 1987. p. 65). Aqueles autores assinalam que "[...] o Estado unitário, dotado de um poder próprio independente de quaisquer outros poderes - começa a nascer na segunda metade do séc. XV na França, na Inglaterra e na Espanha; posteriormente alastra-se por outros países europeus, entre os quais a Itália" (op. cit., p. 24). Isso não significa que a expressão "Estado Moderno" esteja incorreta para denominar o momento de descontinuidade histórica traduzido pela Revolução Francesa; entretanto, há que se cogitar a utilização da expressão para o momento histórico em que a soberania do Estado [vista como independência da autoridade perante qualquer outra] e a distinção entre o Estado e a sociedade civil foi possível estabelecer. 
individualização de poder, mas sim de concentração antifeudal. Como decorrência também há o crescente ressurgimento do fenômeno político até então adormecido, o reforço do aparelho de poder e as transformações intelectuais ${ }^{3}$ daí advindas.

Essas transformações intelectuais acabaram gerando o constitucionalismo, que envolveu o Estado em regras e processos jurídicos estritos, muito arraigados à ideia canônica de direitos temporais e espirituais, já que a Igreja teve papel fundamental nessa "dolorosa" transição (Bobbio, 2004, p. 427). De outra banda, o constitucionalismo também serviu para embasar o Estado Moderno, como um assoalho que viria a legitimar o Liberalismo do novo modelo estatal surgido com a Revolução Francesa.

A última etapa do Estado Liberal ${ }^{4}$ foi o Estado Constitucional de Direito, surgida na crise dos Estados de Direito e Estados Liberais, que veio para embasar e assentar o modelo liberal em bases constitucionais, como quebra do paradigma absolutista e com conotação supralegal.

O Constitucionalismo moderno inglês, em linhas gerais, surgiu no ano de 1215 d.C., com a assinatura da Magna Carta pelo Rei João Sem Terra da Inglaterra. Como explica Dalmo de Abreu Dallari (2003, p. 197-198), os senhores feudais, incomodados com a política adotada pelo monarca, impuseram a assinatura daquela Constituição, que limitou poderes. Registre-se que, "em termos rigorosos, não há um constitucionalismo, mas vários constitucionalismos [o constitucionalismo inglês, o constitucionalismo americano, o constitucionalismo francês]", cada qual surgido ao seu tempo e modo próprios (Canotilho, 2003, p. 51, grifos do autor). Jorge Miranda (2005, p. 45) esclarece no que importou o constitucionalismo:

A Constituição traduz algo de diverso e original. Traz consigo uma limitação nova e envolve todo um modo de ser concebido o poder. Na Constituição se plasma um determinado sistema de valores da vida pública, dos quais é depois indissociável. Um conjunto de princípios filosófico-jurídicos e filosófico-políticos (embora de inspirações algo diversas) vêm-na justificar e vêm-na criar.

Na Inglaterra, no século XVII, a Revolução Inglesa consagrou a supremacia do Parlamento como órgão legislativo, desenvolvendo primitivamente a

3 A redução das categorias sociais e o implemento da presença política do indivíduo, somados ao papel centralíssimo do conceito de "bem-estar" como objetivo da política econômica, foram alguns impulsionadores da tomada de consciência por parte do indivíduo da identidade e da característica comum de seus interesses privados, saindo da atitude passiva para adotar uma postura crítica em relação à gestão estatal (Bobbio, 2004, p. 429).

40 Estado Liberal, primeira faceta do Estado Moderno, se diferenciou do modelo de Estado Absolutista por uma nítida separação entre sociedade civil e poder estatal, cujo mediador era o Direito; uma democracia [do tipo representativa] submetida à ideia de soberania e fulcrada na teoria contratualista do Estado [Rousseau], decorrendo também a chamada teoria escalonada da produção legislativa [Kelsen] exercida por meio do então primitivo controle de constitucionalidade; a ideia de que a função do Estado deveria ser mínima, apenas como garantidor das liberdades individuais, pois era um "mal necessário" (Streck, 2004, p. 87). 
ideia de que o Estado deva ser "um governo de leis, não de homens" (Dallari, 2003, p. 198). Já no continente europeu, as ideias contratualistas e humanistas lutaram contra o absolutismo dos monarcas, preconizando a limitação dos poderes dos governantes, em franca afirmação da supremacia do indivíduo e da racionalização do poder [o que infundiu ao constitucionalismo francês a repercussão universal] (Bobbio, 2004, p. 255). Daí se extrai a ideia de constitucionalismo de J. J. Gomes Canotilho (2003, p. 51):

Constitucionalismo é a teoria (ou ideologia) que ergue o princípio do governo limitado indispensável à garantia dos direitos em dimensão estruturante da organização político-social de uma comunidade. Nesse sentido, o constitucionalismo moderno representará uma técnica específica de limitação do poder com fins garantísticos. (grifos do autor)

Mais aprofundadamente, Karl Lowenstein (1970, p. 152) estabelece que:

Siendo la naturaleza humana como es, no cabe esperar que el detentador o los detentadores del poder sean capaces, por autolimitación voluntaria, de liberar a los destinatarios del poder y a sí mismos del trágico abuso del poder. Instituciones para controlar el poder no nacen ni operan por sí solas, sino que deberían ser creadas ordenadamente e incorporadas conscientemente en el proceso del poder. Han pasado muchos siglos hasta que el hombre político ha aprendido que la sociedad justa, que le otorga y garantiza sus derechos individuales, depende de la existencia de limites impuestos a los detentadores del poder en el ejercicio de su poder, independientemente de si la legitimación de su dominio tiene fundamentos facticos, religiosos o jurídicos. Con el tiempo se ha ido reconociendo que la mejor manera de alcanzar este objetivo será haciendo constar los frenos que la sociedade desea imponer a los detentadores del poder en forma de un sistema de reglas fijas - la constitución - destinadas a limitar el ejercicio del poder político. La constitución se convirtió así en el dispositivo fundamental para el control del proceso del poder.

Ainda, a respeito da relação entre constitucionalismo e democracia, Norberto Bobbio (2004, p. 256) leciona que "seja difícil imaginar em concreto uma democracia não constitucional", pois, para o pensamento democrático, a problemática maior estava em demonstrar como a soberania é um direito imprescritível e inalienável do povo.

Apesar de que hoje "só se concebe o Estado como Estado Constitucional", o Estado Constitucional, para possuir as qualidades identificadas pelo constitucionalismo moderno, deve ser um Estado de Direito Democrático. Entre essas qualidades estão o Estado de direito e o Estado democrático (Canotilho, 2003, p. 92-93):

Fala-se em Estado de direito, omitindo-se a dimensão democrática, e alude-se a Estado democrático, silenciando a dimensão de Estado de direito. Esta dissociação corresponde, por vezes, à realidade das coisas: existem formas de domínio político onde este domínio não está domesticado em termos de Estado de direito e existem Estados de direito sem qualquer legitimação em termos democráticos. O Estado constitucional democrático de direito procura estabelecer uma conexão interna entre democracia e Estado de Direito. (grifos do autor) 
Ainda, registre-se que o Estado Constitucional é "mais" do que o Estado de Direito. Se há a inclusão do elemento "democrático" e que todo o Estado hoje é constitucional, a inclusão da democracia é introduzida pelo reclamo de necessidade de legitimação do poder, pois somente o princípio da soberania popular assegura e garante o direito à igual participação na formação democrática da vontade popular (Canotilho, 2003, p. 100).

A crise do estado de bem-estar ${ }^{5}$ trouxe o neoliberalismo em franco embate com o socialismo, período histórico compreendido a partir de 1960. Todavia, a queda do socialismo soviético, em 1989, levou à crença de que somente o sistema capitalista neoliberal globalizado ofereceria soluções aos anseios sociais, o que, ao contrário, trouxe à tona um Estado Mínimo neoliberal, em que não há diversidade democrática, em que a democracia liberal é o único modelo. Boaventura de Souza Santos (2003, p. 651) denota esse raciocínio:

O fracasso de cada uma dessas três alternativas - ao longo das décadas seguintes - abriu campo para que o liberalismo político e econômico aparecessem juntos como um novo projeto hegemônico, associando Estado mínimo e extensão inédita das relações mercantis, sob a égide do neoliberalismo. O mundo parecia refeito à imagem e semelhança da utopia liberal.

A questão da representatividade ainda restou aberta no tocante às formas de democracia quanto à elaboração e revisão da Constituição do Estado Democrático de Direito, pelo que as teorias de democracia e do poder constituinte [e suas limitações] merecem verificação.

\section{AS TEORIAS DE DEMOCRACIA MAJORITÁRIA E CONSENSUAL}

A definição moderna - e imediatamente o pós-Revolução Francesa - de representação democrática implicou a soberania popular e a destruição de um antigo regime baseado em hereditariedade, direito divino e privilégios [ideia de nação, especialmente nos Estados Unidos e na França].

5 Também chamado de Estado Social ou Welfare State, o Estado de Bem-Estar tem o surgimento bem delineado por Norberto Bobbio (2004, p. 430-431): "Se sobre o plano teórico como no plano da atuação prática, a elaboração de modelos de representação e de associação mais adequados à explanação da sociedade [por causa da entrada nela de novos titulares de novos direitos] e relacionados com o papel qualitativamente diverso que nela desenvolveu a burguesia como força hegemônica levou à recepção dos temas de fundo da doutrina democrática, formalizados no fenômeno do parlamentarismo e do partido de massa, o verdadeiro passo em frente foi, porém, representado pela constituição do Estado como Estado Social, em resposta direta às necessidades substanciais das classes subalternas emergentes. Assistiu-se, por outras palavras, a uma retomada por parte do Estado e do seu aparelho, de uma função de gestão direta da ordem social, mas sobretudo da ordem econômica, cujo andamento natural era agora posto em dúvida pela menor homogeneidade de classe da sociedade civil [...]. O bem-estar voltou a ser o objetivo mais prestigioso da gestão do poder, embora não mais em função declaradamente fiscal e político-econômica, como nos tempos do Estado Absoluto, e sim em vista de um progressivo e indefinido processo de integração social". Daí que Bobbio define o Estado de Bem-Estar, "[...] à primeira análise, como o Estado que garante tipos mínimos de renda, alimentação, saúde, habitação, educação, assegurados a todos os cidadãos, não como caridade, mas como direito político. [...] Na realidade, o que distingue o Estado assistencial de outros tipos de Estado não é tanto a intervenção direta das estruturas públicas na melhoria do nível de vida da população quanto ao fato de que tal ação é reivindicada pelos cidadãos como um direito" (op. cit., p. 416). 
Alain Touraine (1994, p. 341) afirma que posteriormente, no século XIX, os crescentes problemas econômicos levaram ao surgimento da ideia de soberania popular como "poder a serviço dos interesses da classe mais numerosa" e à substituição da ideia de "nação" por "povo", que se transformou em "classe operária".

O mesmo autor refere que "a ideia de democracia, inicialmente identificada à de sociedade, aproximou-se progressivamente da ideia de Sujeito, do qual ela tende a tomar-se a expressão política" (1994, p. 341).

Daí que as diferenciações entre os diferentes modelos de democracias - de um lado a majoritária [ou modelo Westminster ${ }^{6}$, e de outro a consensual - são relevantes para verificar até que ponto é legítimo o poder de reforma da constituição em matéria de direitos fundamentais.

\subsection{MODELO MAJORIT́RIO DE DEMOCRACIA}

O modelo majoritário de democracia também é chamado de modelo Westminster, porque é adotado no Reino Unido e é ou foi exportado para ex-colônias britânicas [a exemplo da Nova Zelândia e de Barbados].

Arend Lijphart (2003, p. 27-28) estabelece dez critérios, elementos ou características inter-relacionados para verificação de se tratar de um tipo de modelo de democracia ou de outro. Tais critérios podem ser assim dispostos:

1) Concentração do Poder Executivo [gabinete unipartidário ou de maioria mínima, ou gabinete de ampla coalizão];

2) Preponderância [ou não] do Poder Executivo sobre o Poder Legislativo;

3) Sistema partidário [bipartidário ou multipartidário];

4) Sistema de eleições [majoritário e desproporcional ou proporcional];

5) Grupos de interesse [pluralismo ou corporativismo];

6) Distribuição de competências governamentais em regiões [unitário e centralizado ou federal e descentralizado];

7) Concentração do Poder Legislativo [unicameral ou bicameral];

8) Reforma constitucional [flexibilidade ou rigidez];

9) Controle de constitucionalidade das leis [ausência de revisão judicial ou permissibilidade do Judiciário controlar a constitucionalidade das normas]; 
10) Controle do Banco Central Nacional [submisso ao Poder Executivo ou independente].

A partir da elaboração dos critérios inter-relacionados, Lijphart elaborou estudo em que constatou que, no governo britânico, o gabinete é o órgão mais poderoso, sendo formado por membros do partido majoritário nas cadeiras da Câmara dos Comuns. A minoria não é incluída e são raros os casos de gabinetes de coalizão. Daí porque o nome do modelo é "majoritário". O sistema é bipartidário, com partidos de força aproximadamente igual. Por isso, há maioria estreita [ou mínima], e, por conseguinte, "minoria grande". O poder político é manobrado inteiramente pelo partido majoritário, governando no interesse dessa maioria (2003, p. 28-29).

Nesse modelo, o bipartidarismo é o responsável pela preponderância do Executivo sobre o Legislativo ["Ditadura Eletiva" - expressão cunhada por Lorde Hailsham], e não o parlamentarismo em si, já que o multipartidarismo implicaria em gabinetes de coalizão, enfraquecendo o Executivo e equilibrando-o com o Parlamento (Lijphart, 2003, p. 29-30).

Ainda, nesse modelo de democracia de regra, as constituições são "não escritas", não existe um documento único contendo as competências, a forma de organização governamental e os direitos dos cidadãos. Em vez disso, há poucas leis básicas, além de princípios, costumes e convenções. Nesse modelo, a Constituição é inteiramente flexível, podendo ser alterada pelo Parlamento sem imposição de requisitos específicos [p. ex., quórum qualificado] (Lijphart, 2003, p. 36).

Como consequência da flexibilidade no procedimento de reforma constitucional, não há controle de constitucionalidade, ou seja, a total ausência de revisão judicial de normas que supostamente contrariem a constituição, até porque esta é "não escrita". O Parlamento normalmente aceita e se sente ligado às regras da constituição "não escrita"; entretanto, ele não está preso a elas. Por isso, o Parlamento [a maioria parlamentar] é a autoridade máxima/ soberana, significando que o Parlamento tem, pela constituição "não escrita", a competência para desfazer qualquer lei, e os países que adotam esse modelo de democracia não reconhecem os direitos de ninguém para anular ou rejeitar a legislação do Parlamento, com poucas exceções como a União Europeia (Lijphart, 2003, p. 36-37).

Jeremy Waldron (2003, p. 186-187) afirma que, apesar de a deliberação ser importante, os seres humanos tendem a discordar entre si no campo da política e da justiça, tanto antes quanto após a deliberação. Para o autor, essa ideia é mais que realista, é uma perspectiva a ser considerada como uma das condições elementares da política moderna: tudo que se diz sobre política deve necessariamente levar em consideração essa ideia, sob pena da política não fazer muito sentido. Por isso, de acordo com aquele autor, muito da democracia deliberativa parece sonho. 
John Rawls (2008, p. 126-129) diz que uma diversidade de doutrinas abrangentes, conflitantes e irreconciliáveis é mais do que uma condição histórica passageira: é uma característica permanente da cultura democrática. A discordância é a característica mais proeminente das democracias modernas, e uma questão de justiça deve ser necessariamente uma questão de agir conjuntamente, com base em uma visão comum. Mas isso necessariamente não faz desaparecer a discordância; pelo contrário: a base comum para a ação deve ser forjada no calor das discordâncias, e não repousar no "consenso sereno" que é apenas ideal (2008, p. 130).

No outro plano, está o modelo de democracia consensual, que demanda uma análise própria.

\subsection{MOdeLO CONSENSUAL DE DEMOCRACIA}

Os mesmos dez critérios, elementos ou características inter-relacionados criados por Arend Lijphart para a verificação dos modelos de democracia são, obviamente, aplicáveis para o modelo consensual.

Esse modelo é visualizável em alguns países como a Suíça, a Bélgica e em organismos internacionais como a União Europeia, cada qual com seu grau de consensualidade próprios.

Quando as sociedades são relativamente homogêneas e houver alternância no governo entre maiorias e minorias, a incompatibilidade poderia ser resolvida desde que os interesses dos eleitores sejam razoavelmente atendidos pelo outro partido ["governo para o povo"] (Lijphart, 2003, p. 52).

Entretanto, nos países em que não há essa homogeneidade, Arthur Lewis, citado por Lijphart (2003, p. 51), afirma que o governo pela maioria e a situação de "governo versus oposição" podem ser vistos como antidemocráticos, na medida de significarem exclusão, pois todos os afetados por uma decisão devem ter a oportunidade de participar do processo que a originou, quer diretamente, quer por seus representantes escolhidos.

O fato de "a vontade da maioria deve prevalecer" [pressuposto básico da democracia] parece incompatível com o modelo consensual e, portanto, antidemocrático, pois se partiria de uma premissa de que os grupos perdedores são excluídos da participação nos processos decisórios, cujas minorias terão sistematicamente negado acesso ao poder.

Para esses países onde há certo grau de heterogeneidade nos interesses dos eleitores ${ }^{7}$, a democracia de consenso será aquela que estimule a coalizão

7 Marcadamente por insistência na representatividade proporcional, coalizões e federalismo, medidas recomendadas por Arthur Lewis para as sociedades plurais subdesenvolvidas (Lijphart, 2003, p. 53). 
em vez da oposição, promova a inclusão ao invés da exclusão, e tente ampliar a maioria governante ao invés de satisfazer uma pequena maioria.

Jeremy Waldron (2003, p. 183), antes de criticar o modelo de democracia consensual, assinala que uma legislação parece arbitrária quando é resultado de uma decisão majoritária, pois se basearia apenas em números, substituindo o processo de deliberação arrazoada pela aritmética da contagem de votos. Assim, Waldron (2003, p. 184) refere:

Os pensadores modernos da democracia deliberativa enfatizam conversação e unanimidade. Consenso racionalmente motivado é o objetivo da deliberação. Havendo duas ou mais pessoas persistentes num argumento, significa que há possibilidade de, ao fim, as considerações convencerem a todos.

Seja em relação ao modelo de democracia majoritária, seja em relação ao de democracia consensual, a partir da ideia unificadora de soberania popular, passou-se para a ideia de defesa de direitos, em primeiro lugar do direito dos governados de escolherem seus governantes [como já visto na primeira seção acima], e também estabelecendo limites ao combater a ideia de individualismos extremos que podem dissociar completamente a sociedade civil da sociedade política, deixando-a entregue ao poder usurpador de totalitarismos (Touraine, 1994, p. 343).

Em relação à democracia consensual, há que se fazer a ressalva de que nem sempre as considerações terão permissão para convencer a todos de forma a suprimir ou modificar determinados direitos estabelecidos pelo processo constitucionalizante, ao que se pode denominar de teoria do coto vedado, o que será abordado no item 4.

\section{A DEMOCRACIA PARTICIPATIVA DIRETA COMO DIREITO SOCIAL}

O constitucionalismo atual se defronta com um de seus maiores problemas: a dicotomia entre os direitos de liberdades e garantias [vistos como de primeira dimensão/geração ${ }^{8}$ ] e os direitos sociais, porque estes últimos, apesar de expressamente qualificados como direitos fundamentais, não se beneficiam do regime jurídico específico previsto para os direitos de liberdades e garantias, como se vê do art. 60, § 4º , inciso IV, da Constituição Federal (Miranda, 2005, p. 311).

Para Peter Häberle (1997, p. 43), no âmbito de uma "otimização" ou de uma "efetividade de gozo" dos direitos fundamentais, deve-se distinguir

8 Aqui, a discussão sobre qual terminologia é a mais correta para a definição das "ondas evolutivas" dos direitos fundamentais, seja pela expressão "dimensão" ou "geração", é irrelevante, porque em qualquer caso, conforme estudos de Ingo Wolfgang Sarlet, "a teoria dimensional dos direitos fundamentais não aponta, tão somente, para o caráter cumulativo do processo evolutivo e para a natureza complementar de todos os direitos fundamentais, mas afirma, para além disso, sua unidade e indivisibilidade no contexto do direito constitucional interno e, de modo especial, na esfera do moderno 'Direito Internacional dos Direitos Humanos'" (2009, p. 45-46). 
[...] a história dos direitos fundamentais, que pressupõe uma concepção jurídica e cultural dos direitos em termos de 'passado", da dogmática dos direitos fundamentais, que pressupõe uma comparação jurídica e cultural desses direitos em termos de "presente". A essas duas dimensões deve-se acrescentar uma terceira: uma política dos direitos fundamentais, consistente na compreensão jurídica e cultural dos direitos fundamentais em termos de "futuro".

Cumpre esclarecer que "a diferença entre a natureza de 'expectativas negativas' dos direitos de defesa [de liberdades] e a natureza de 'expectativas positivas' dos direitos fundamentais sociais" não é suficiente para descaracterizar os segundos como direitos fundamentais, "incluindo expectativas de ambos os tipos" (Queiroz, 2006, p. 07).

Para além disso, J. J. Gomes Canotilho (2004a, p. 51) complementa esse o raciocínio da autora acima referida:

Ao não existir uma diferenciação de natureza entre os diferentes tipos de direitos fundamentais, cai por terra a "tese da inexigibilidade intrínseca" dos direitos fundamentais sociais. Os clássicos direitos de defesa [...] requerem, por parte da esfera pública, obrigações de prover as numerosas e complexas condições institucionais do respectivo exercício e garantia.

Trazendo para o contexto da democracia, Peter Häberle (1997, p. 09) refere uma "realização cooperativa" dos direitos fundamentais:

Esta pressupõe a existência de um espaço público comum e um modelo politicamente organizado de sociedade no qual cada homem livre se possa incorporar, sendo possível reclamar para a "vocação moral do cidadão" [Smend] uma concepção e autocompreensão abrangentes que tenham em conta o sistema de correlações e condicionamentos recíprocos entre os aspectos individual e social desses direitos em contextos supraindividuais - direitos fundamentais como fundamento funcional da democracia.

Dessa forma, os direitos fundamentais passam a ser entendidos e interligados em uma relação unificadora, em contraponto ao aspecto inicialmente designado como de reserva/barreira ao poder do Estado. Por conseguinte, para Cristina Queiroz (2006, p. 20), o "estatuto de cidadania não se define, basicamente, por meio de um modelo de liberdade de caráter essencialmente 'negativo'; antes através de um estatuto de direitos cívicos, concebidos como 'liberdades positivas'".

John Rawls (2008, p. 131), Ronald Dworkin (2003, p. 179) e Jürgen Habermas (2003, p. 109) concordam em um ponto: o de que, conforme modernas "teorias republicanas", a ideia dominante no modelo liberal [que relacionava a ideia de liberdade como um conceito "negativo", significando a ausência de interferência estatal na vida dos governados] é impugnada em razão de uma concepção "positiva" [pela qual o indivíduo será livre na medida em que for possível dispor dos meios e recursos imprescindíveis à concretude de seus próprios planos de vida: o autogoverno ou a própria autorrealização pessoal]. 
Por tais razões, Peter Häberle (1997, p. 42) e Konrad Hesse (1991, p. 39) defendem a ordenação de um "sistema de correlações" entre os aspectos "individual" e "social" desses direitos em "contextos supraindividuais". Daí porque é de todo relevante uma concepção "nova" de direitos que permita uma correlação entre os direitos "clássicos" de liberdade e os modernos direitos de participação, implicando uma redefinição de direitos e colocando no mesmo plano a dimensão "negativa" e a dimensão "positiva" dos direitos fundamentais.

Em consequência desse raciocínio, Cristina Queiroz (2006, p. 29) entende que os direitos em sentido clássico podem se apresentar como direitos a prestações. Ela cita como exemplos "neste caso o direito de voto, o direito a uma tutela ou defesa efectiva dos direitos na sua integralidade ou o dever, que incumbe ao Estado, de criação de normas procedimentais e organizativas, que, de algum modo, requerem uma prestação estadual". Nesse mesmo sentido, J. J. Gomes Canotilho (2004b, p. 07) esclarece:

[...] a cidadania não consiste unicamente em proteger uma esfera de liberdade face ao Estado. Pelo contrário, a cidadania encontra-se hoje inextrincavelmente ligada ao controle do poder público. Esse controle deve ser garantido através de mecanismos de participação, segurança e independência (isto é, "não dominação") e não por simples barreiras erguidas contra o poder do Estado (walls against the State). [grifos do autor]

Daí porque a funcionalidade, a abrangência, a amplitude do direito fundamental à participação democrática fazem incorrer os cidadãos em expectativas e pretensões, isto é, aquilo que os cidadãos têm "direito" a esperar [were entitled to expect], adquirindo os direitos fundamentais um sentido qualitativo diferenciado (Queiroz, 2006, p. 31).

Isso significa que, da parte dos direitos "negativos", é possível existirem pretensões "positivas", ou seja, face ao legislador, o grau de vinculação desses direitos acaba por se traduzir em um maior "espaço de prognose" e "liberdade de conformação", que se traduz na determinação de diferentes tipos de "margens de ação" (Queiroz, 2006, p. 32).

A confirmar essa ideia, advogada neste trabalho está a posição de Böckenförde (apud Queiroz, 2006, p. 33):

Esta concepção da liberdade leva a um alargamento e extensão do conceito de direitos de participação originários. É o conceito de liberdade interpretado em sentido positivo, como liberdade real, que funda uma concepção dos direitos fundamentais no Estado social.

Isso acaba por permitir a ilação de que, antes de ser apenas um direito fundamental de primeira geração/dimensão, o direito à cidadania ativa é também um direito prestacional positivo [de segunda geração/dimensão], a ser exercido em face do Estado quando este se mostrar omisso a tal respeito. 


\section{A TEORIA DO COTO VEDADO}

Tanto a concepção unanimista popular de democracia [que serviu para acobertar regimes totalitários] quanto concepções daqueles que desejam a deterioração do Estado e do sistema político [depositando toda a confiança no mercado, estendendo-o ao ponto de dominar as decisões políticas] devem ser afastadas, pois é imperioso reconhecer que a democracia repousa hoje sobre: a) a livre escolha dos dirigentes; e b) a limitação do poder político.

De qualquer sorte, a liberdade de escolhas políticas, o respeito às identidades, às necessidades e aos direitos [pressupostos básicos da cidadania ${ }^{9}$ ] não podem servir para suprimir exatamente o direito de determinação democrática de um povo.

Alain Touraine (1994, p. 345) afirma que a concepção positiva da liberdade, vista como realização da soberania popular, cedeu lugar a uma concepção negativa, e a democracia é definida e defendida como o regime que impede - seja lá quem for - de se apropriar do poder ou de conservá-lo contra a vontade da maioria.

Para Jeremy Waldron (apud Bayon, 2010, p. 72), o modelo de democracia majoritário, em que o constitucionalismo é fraco e não há controle de constitucionalidade, é o único que reconhece e toma a sério a igual capacidade de autogoverno das pessoas, o direito de todos de ter a sua voz em conta. Isso conferiria à regra da maioria um valor moral que faria carecer qualquer outro procedimento de decisão coletiva [a exemplo do modelo consensual].

Dessa afirmação deriva um problema bem mais profundo e complexo de resolver: e quando a própria maioria resolve decidir, de forma irretratável, que não deve mais ter a democracia ao seu favor, abdicando do poder de decidir?

Obviamente que tal situação implica prejuízo para alguém e lucro para outrem. A coletividade seria prejudicada em detrimento do grupo dominante que passaria a tomar as decisões sem ser necessário nem sequer prestar contas de seus atos. A ação política do povo seria absolutamente suprimida, inclusive quanto à possibilidade de retomar seu poder.

Então haveria problema de justificação e de legitimidade, afirmação que encontra eco na visão de Friedrich Müller (2009, p. 39):

O termo "democracia" não deriva apenas etimologicamente de "povo". Estados democráticos chamam-se governos "do povo" ["Volks"herrrschaften]; eles

9 Cidadania é a qualidade de ser cidadão. Cidadão é o membro do Estado, o destinatário da ordem jurídica estatal, o sujeito e o súdito do poder. A palavra "nacionalidade" deve ser afastada do sentido de cidadania, pois aquela tem a ver com a nação, e não a um Estado. Enquanto nacionalidade denota termo de maior extensão [pois se relaciona ao coletivo de pessoas e pode ser atribuída às coisas], a cidadania só diz respeito a pessoas singulares. Cidadania significa, ainda, a participação em um Estado Democrático, cuja perspectiva de que o conceito foi elaborado e se difundiu após a Revolução Francesa, parecendo reservar-se, por vezes, para a cidadania ativa, correspondente à capacidade eleitoral (Miranda, 2005, p. 204-205). 
se justificam afirmando que em última instância o povo estaria "governando" ["herrscht"].

Todas as razões do exercício democrático do poder e da violência, todas as razões da crítica da democracia dependem desse ponto de partida.

Mas como impedir que o poder da democracia faça com que o povo se autodestitua de seu poder, erigido constitucionalmente, em prol de um grupo totalitário?

Tentando responder a essa pergunta, Juan Carlos Bayon (2010, p. 01) cita Ernesto Garzón como o primeiro a cunhar a expressão coto vedado para designar

[...] la específica configuración estructural resultante de los rasgos mencionados, que suele resumirse diciendo que los derechos básicos retiran ciertos temas de la agenda política ordinaria para emplazarlos en esa esfera intangible [...].

Isso significa, nas palavras de Bayon (2010, p. 01), que a ideia de direitos básicos ou fundamentais é normalmente definida a partir da combinação de duas características: a) os direitos básicos são limites para a adoção de políticas que devem salvaguardar incondicionalmente cada indivíduo, colocando-os a salvo de quaisquer sacrifícios; e b) trata-se de limites absolutos, intocáveis ao procedimento de tomada de decisões que a maioria não deve decidir, estando acima destas.

Daí que a teoria do coto vedado retrata compromisso com a estrutura institucional que é o constitucionalismo. É comezinho que o constitucionalismo tem uma conta pendente em relação ao que se denomina "objeção contra a maioria", pois: a) Se a democracia é o método de tomada de decisões pela maioria, a primazia constitucional implica precisamente em restringir ao que a maioria pode decidir; e b) Qual a legitimidade têm os Juízes não representativos democraticamente para invalidar decisões do legislador votado democraticamente?

A questão é mais simples relativamente às reformas constitucionais, que, no Brasil, a Constituição Federal de 1988 estabelece, no art. 60, § 4ํㅡㄴ, o seguinte (Brasil, 2010):

Art. 60. A constituição poderá ser emendada mediante proposta:

$[\ldots]$

$\S 4^{\circ}$ Não será objeto de deliberação a proposta de emenda tendente a abolir:

I - a forma federativa de Estado;

II - o voto direto, secreto, universal e periódico;

III - a separação dos Poderes;

IV - os direitos e garantias individuais. 
Desse texto é possível extrair a necessidade de voto periódico, além de que os direitos e garantias individuais - aí incluídos os direitos à participação política - são considerados cláusulas pétreas, sem falar na situação de que "todo o poder emana do povo, que o exerce por meio de representantes eleitos ou diretamente, nos termos desta Constituição" (Brasil, 2010).

As teses de amplitude das reformas constitucionais levam em conta os contextos intrínsecos das cláusulas pétreas e dos princípios gerais do Direito pulverizados pela Carta, que também podem ser chamados de limites imanentes ao poder constituinte derivado. J. J. Gomes Canotilho (2003, p. 1165) aduz o seguinte:

A ideia de limitação do poder de revisão não pode divorciar-se das "conexões de sentido" captadas no Texto Constitucional. Desta forma, os limites materiais devem encontrar um mínimo de recepção no Texto Constitucional, ou seja, devem ser "limites textuais implícitos". No entanto, ao aceitarem-se limites imanentes deduzidos a partir do "telos" constitucional, então terá de exigir-se que esses limites não sejam meros "postulados", mas autênticas imposições da constituição, verdadeiros limites impostos pela vontade da Constituição.

Também Streck (1993, p. 38-39), de forma concisa, assevera:

Tais vedações - implícitas - são limitações de reforma produzidas pela própria estrutura do discurso pelo qual se expressa a Constituição. São aquelas que se originam dos paradigmas adotados pelo próprio sistema jurídico e que definem, com alguma clareza, quais as normas que a ele pertençam ou possam pertencer.

Para o caso específico do Brasil, além dos atuais legisladores ordinários não possuírem competência para produzir emendas que excluam ou contrariem - mesmo que indiretamente - princípios que digam respeito a direitos fundamentais, pois detêm legitimidade tão somente para alterar normas que não digam respeito àquelas matérias enumeradas no $\S 4^{\circ}$ do art. 60 da Constituição $^{10}$, as emendas não podem versar - mesmo implicitamente - sobre questões que sejam "tendentes a abolir" direitos fundamentais, entre eles o direito de determinação democrática do povo.

Relativamente à sentença "tendente a abolir" contida no art. $60, \S 4^{\circ}$, da Constituição de 1988, é visível a dificuldade de se delinear o exato conteúdo das limitações [sejam expressas ou implícitas] constantes das cláusulas pétreas. Porém, diante da dificuldade, convém afirmar as poucas certezas. Nesse sentido, José Carlos Francisco (2003, p. 83):

10 As Cartas contêm princípios de valor e alcance distintos, porém com reflexos constantes sobre o poder de alteração. Essa diversidade gera dúvidas. Em uma Constituição, há princípios expressos, princípios inerentes, princípios implícitos, princípios resultantes, princípios fundamentais e princípios circunstanciais. Todos eles pertencem tanto à Constituição quanto os explícitos. Porque a Constituição proíbe expressamente apenas os projetos tendentes a abolir as cláusulas pétreas, somente a insânia poderia concluir que tudo o mais é permitido (Mangabeira, 1980, p. 104). 
É certo que essa expressão "tendente a abolir" possibilita projetos de emendas que visem ampliar as previsões constantes desse preceito constitucional, ou seja, não levem prejuízo (mas sim reforço) aos institutos tratados nesse mesmo $\S 4$. Afinal, claramente se sabe que previsões como a do art. $60, \S 4^{\circ}$, da Constituição de 1988 visam assegurar determinados princípios, e não os dispositivos (ou a forma dos preceitos) que os expressam.

Ao ser dado efetivo alcance à expressão "tendente a abolir", restam proibidas tanto as propostas de emendas que diretamente prejudiquem as cláusulas pétreas, assim como as que indiretamente modifiquem negativamente tais pontos (Horta, 1999, p. 18). E prossegue:

A interpretação da proposta de emenda tendente a abolir não se detém na emenda frontal, grosseira, rombuda, aleijão jurídico escandaloso, para abranger na sua eficácia proibitória a proposta oblíqua, indireta, sinuosa, capaz, pelos seus efeitos nocivos, de incorrer no comprometimento da irreformabilidade e na virtual abolição da regra e do princípio protegidos pela intangibilidade.

Paulo Bonavides (1985, p. 235), em plena discussão da constituinte, ponderou:

A par das limitações materiais, deparam-se-nos ainda limitações provenientes também do conteúdo que se pretende constitucionalizar. Não se concebe determinados retrocessos. Ninguém admitiria, assim, que uma mudança constitucional abolisse garantias sociais básicas.

Mudanças dessa magnitude infringem a relação de pertinência e o sistema jurídico criado pela Constituição, atingindo seu núcleo político, o que J. J. Gomes Canotilho (2003, p. 1065-1066), chama de "alterações constitucionais aniquiladoras da identidade de uma ordem constitucional histórico-concreta".

Lênio Luiz Streck (1993, p. 39) afirma que os limites imanentes impediriam, em tese, as emendas que desfigurassem "o sistema de seguridade social, liberdade de imprensa, anterioridade dos impostos, etc.", praticamente prevendo que o poder executivo, baseado na conjectura de exigir muito e não retribuir nada, viria a solapar ainda mais os [desrespeitados] direitos fundamentais.

De outra banda, poder-se-ia cogitar que o Poder Constituinte derivado pretendesse a modificação dos limites processuais ou formais de reforma constitucional. Autores como José Afonso da Silva apontam no sentido da impossibilidade de o Poder Reformador alterar as regras previstas para o processamento das emendas ${ }^{11}$. Há, por outro lado, autores que acolhem a possibilidade de modificação dos limites procedimentais fixados ao Poder Constituinte revisional ${ }^{12}$.

11 No sentido da impossibilidade, José Afonso da Silva (2006, p. 59-60). O mesmo autor também afirma a possibilidade de se modificar o mecanismo de emendas apenas para torná-lo mais agravado, sendo que representa limitação implícita modificá-lo para flexibilizá-lo (2000, p. 245).

12 No sentido da possibilidade, Tércio Sampaio Ferraz Júnior (1985, p. 135) e Raul Machado Horta (1999, p. 114). 
No entanto, essa complexa questão envolve dois sentidos da expressão "poder constituinte": a) o poder-força política [para o qual não existem limites]; e b) competência jurídica [segundo a qual a modificação que se quer levar a efeito nos procedimentos deve, no entanto, e em um primeiro momento, seguir exatamente as regras procedimentais que se pretende modificar] (Francisco, 2003, p. 86).

É certo que se trata de ideia complexa e controversa, na medida em que o órgão revisor se transformou em órgão constituinte originário. Todavia, há que se valorizarem os limites processuais, na medida em que a rigidez constitucional neles contempladas serve à estabilidade [pelo grau de dificuldade e reflexão exigidos] e à legitimidade democrática [pela maioria qualificada] nas mudanças constitucionais (Canotilho, 2003, p. 1067).

Mas, como dito, essas situações de limites imanentes referem-se à situação de reforma constitucional. E quando no próprio poder constituinte está imbuída a ideia de supressão do poder democrático pelo próprio povo? E quando o poder constituinte já pretender, antes mesmo da promulgação da Constituição, abrir mão de seu poder democrático em favor de um grupo ou de uma pessoa?

Um dos mecanismos que garante a teoria do coto vedado é a existência de controle jurisdicional de constitucionalidade, instrumento que, em tese, poderia ter atuação preventiva ou até mesmo como remédio diante de tal crise do poder democrático (Bayon, 2010, p. 66).

Os críticos do controle de constitucionalidade afirmam que o juiz constitucional invalida decisões do legislador democraticamente eleito, utilizando-se de critérios discricionários e não democráticos.

Todavia, os princípios constitucionais que declaram direitos fundamentais são formulados em termos vagos e abstratos, dependendo de toda a teoria da argumentação e do discurso jurídico para serem formulados e posteriormente lidos (Alexy, 2008, p. 551), fazendo cair por terra a crítica [formulada de forma mais lúcida e de consequências mais radicais por Jeremy Waldron].

\section{A TUTELA DA PARTICIPAÇ̃̃O EFETIVA NO PROCESSO DEMOCRÁTICO}

Do que se viu nas seções anteriores, a evolução do Estado Moderno e do constitucionalismo, permitindo condições propícias para a concretização da democracia na grande maioria dos países ocidentais, bem como as teorias dos modelos democráticos e a teoria do coto vedado, além da nova perspectiva do direito à participação democrática como sendo não apenas um direito de liberdade, mas também um direito fundamental social, é possível agora estabelecer relação a democracia materialmente vista e sua efetivação por meio da tutela jurisdicional.

A "democracia débil" é argumento utilizado por John Hart Ely (2010, p. 159) como exceção possível para a utilização do ativismo judicial em matéria 
de efetivação do princípio da democracia participativa. No mesmo sentido, o pensamento de Oscar Vilhena Vieira (2006, p. 623-624).

Tal argumento parte do pressuposto de que a democracia representativa causa distorções na realização da vontade geral e isso influi na distribuição final da justiça social a ser realizada pelos representantes eleitos pelo povo.

Como corolário, se todo o poder emana do povo [art. 1o da CF/1988], tal representa uma norma de cunho principiológico da Constituição, no sentido de que quando se define as formas de exercício da democracia, há evidente preponderância da forma direta sobre a forma representativa.

Todavia, não é isso o que ocorre atualmente no Brasil, pois, em mais de duas décadas desde a promulgação da Carta de 1988, o referendo popular ${ }^{13}$ foi convocado apenas uma vez pelo Congresso Nacional, a quem compete a convocação de referendos e plebiscitos, regra que reduz o princípio constitucional da democracia participativa.

Como a democracia participativa não é apenas um direito de liberdade, mas também um direito prestacional a ser exercido em face do próprio Estado, e tendo em vista o princípio do acesso à justiça, visto como a possibilidade de quem possua legitimidade e interesse pleitear perante o Poder Judiciário a prevenção e/ou reparação por eventual ameaça ou lesão a direito [art. 5ํㅡㄴ inciso XXXV, da CF/1988], tem-se que a não efetivação do direito à participação no processo democrático viola, em tese, preceito fundamental.

Conforme Celso Ribeiro Bastos e Alexis Galiás de Souza Vargas (2000, p. 37), preceito fundamental diz respeito a algumas matérias da Constituição que, dadas a magnitude e a posição que ocupam na Carta, não deixam dúvidas quanto à caracterização como fundamentais: soberania, cidadania, dignidade da pessoa humana, valores sociais do trabalho e da livre iniciativa, pluralismo político, forma federativa de Estado, voto direto, secreto, universal e periódico, separação dos poderes e os direitos e garantias individuais.

Para José Afonso da Silva (2006, p. 488), a expressão "preceitos fundamentais" não se confunde com "princípios fundamentais", já que aquela é mais ampla do que esta. "Preceito fundamental" abrange todas as prescrições que

13 No Brasil, o princípio da democracia semidireta representa a combinação da democracia representativa com a democracia direta (Benevides, 2003, p. 129). Os meios estabelecidos para o exercício da democracia semidireta foram o referendo, o plebiscito e a iniciativa popular. Quanto à distinção entre referendo e plebiscito, Canotilho (2003, p. 295) diz que o primeiro é "uma consulta feita aos eleitores sobre uma questão ou sobre um texto através de um procedimento formal regulado na lei". Já no segundo a população se pronuncia sobre escolhas ou decisões políticas, a exemplo da opção por uma ou outra forma de governo (Benevides, 2003, p. 36). Há ainda o instrumento do recall, que "tem aplicação em duas hipóteses diferentes: ou para revogar a eleição de um legislador ou funcionário eletivo, ou para reformar decisão judicial sobre constitucionalidade de lei $[. .$.$] exigindo, no primeiro caso, que um certo número de eleitores requeira uma consulta à opinião do$ eleitorado sobre a manutenção ou revogação do mandato conferido a alguém, exigindo-se dos requerentes um depósito em dinheiro" (Dallari, 2003, p. 154-155). Isso se deve porque a Constituição de 1988 não deixou margem para outras manifestações de democracia direta ou semidireta senão aquelas expressamente elencadas no art. 14. 
dão o sentido básico do regime constitucional, como, por exemplo, as referentes à autonomia das unidades federadas e aos direitos e garantias fundamentais.

Apesar de haver trabalho em sentido contrário (Bustamante, 2000), não se acredita que a expressão "preceito fundamental" envolva toda a matéria presente na Carta, porque, do contrário, seria desnecessário o predicado "fundamental", bastando que o constituinte tratasse de uma "arguição de descumprimento de preceito constitucional". Além disso, o próprio caráter excepcional do instrumento legitima uma interpretação restritiva.

Entretanto, não se vislumbra que o objeto da ADPF reduza-se aos princípios fundamentais e aos direitos e garantias fundamentais (Títulos I e II). Para Carlos Antônio de Almeida Melo (2000, p. 115), "preceito fundamental" equivale

[...] ao conceito de constituição material. Configuram preceitos fundamentais aqueles que contêm normas estruturais do Estado e da sociedade nos seus aspectos fundamentais, ou seja, questões de natureza macroestrutural, de anatomia do Estado e da sociedade, configurando a pauta mínima do Texto Constitucional, como normas nucleares de todo o edifício normativo estatuído na Constituição. Assim, normas básicas da organização do Estado, de formas e de exercício do poder, normas assecuratórias de direitos individuais, coletivos e sociais integram, necessariamente a categoria.

Nas palavras de André Ramos Tavares (2001, p. 249), a arguição de descumprimento de preceito fundamental [ADPF] tem o seguinte conceito:

A arguição é ação judicial, de competência originária do Supremo Tribunal Federal, que desencadeia o denominado processo objetivo, cujo fundamento é o descumprimento de preceito constitucional que consagra valores basilares do Direito pátrio, descumprimento este perpetrado por ato de natureza estatal.

Do que se infere, a disposição de que "todo o poder emana do povo" retrata princípio, e a disposição de que "é da competência exclusiva do Congresso Nacional: [...] autorizar referendo e convocar plebiscito" [art. 49, inciso XV, da CF/1988] retrata regra. Conforme lição de Robert Alexy (2008, p. 90-91 e 109), a situação de colidência entre princípios e regras permite aquinhoar os primeiros como prevalentes:

O ponto decisivo na distinção entre regras e princípios é que princípios são normas que ordenam que algo seja realizado na maior medida possível dentro das possibilidades jurídicas e fáticas existentes. Princípios são, por conseguinte, mandamentos de otimização [o conceito de mandamento é aqui utilizado em um sentido amplo, que inclui também as permissões e as proibições], que são caracterizados por poderem ser satisfeitos em graus variados e pelo fato de que a medida devida de sua satisfação não depende somente das possibilidades fáticas, mas também das possibilidades jurídicas. O âmbito das possibilidades jurídicas é determinado pelos princípios e regras colidentes.

Já as regras são normas que são sempre ou satisfeitas ou não satisfeitas. Se uma regra vale, então deve se fazer exatamente aquilo que ela exige; nem mais, nem 
menos. Regras contêm, portanto, determinações no âmbito daquilo que é fática e juridicamente possível. [...] Toda norma é ou uma regra ou um princípio. [...]

As razões para que as outras múltiplas características dos princípios são óbvias. Enquanto razões para regras de natureza muitas vezes bastante técnica, o conteúdo axiológico dos princípios é mais facilmente identificável que o das regras; como razões decisivas para inúmeras regras, os princípios têm uma importância substancial fundamental para o ordenamento jurídico; sua relação à ideia de direito decorre de um modelo de fundamentação que avança do mais geral na direção do sempre mais especial; e a contraposição dos princípios, enquanto normas "desenvolvidas", às normas "criadas" deve-se à desnecessidade de que os princípios sejam estabelecidos de forma explícita, podendo decorrer de uma tradição de positivação detalhada e de decisões judiciais que, em geral, expressam concepções difundidas sobre o que deve ser o direito. (grifos do autor)

Portanto, a utilização da tutela jurisdicional por meio da ADPF com vistas à concretização do direito fundamental à democracia participativa afigura-se como possível e pertinente, mormente em razão da atual subversão na utilização das formas do poder democrático, em que inegavelmente a forma representativa está indevida e ilegitimamente preponderando.

\section{CONCLUSÃO}

Independentemente das situações já expostas, a questão de fundo permanece em aberto, porque, apesar de o Tribunal Constitucional poder atuar, o fato é que, se a regra da maioria funciona como procedimento de decisão não sujeito a restrições substantivas, por meio dela seria possível, em tese, adotar decisões com qualquer conteúdo, podendo, portanto, inclusive decidir por suprimir sua própria vontade democrática.

Essa questão ganha contornos palpáveis ao se verificar a crescente onda de caudilhismo na América Latina, a exemplo de chefes de Estado que propuseram a modificação de Constituições para permitir reeleições indefinidas no tempo, imprimindo o que Lorde Hailsham, citado por Arend Lijphart (2003, p. 30), denomina de "Ditadura Eletiva".

Jeremy Waldron, citado por Juan Carlos Bayon (2010, p. 71), afirma que:

[...] el constitucionalismo estabelece que hay cosas que las mayorías no pueden decidir es contar una historia incompleta: porque antes, en ausencia más que previsible de unanimidad al respecto, ha habido que tomar de algún modo la decisón sobre qué es lo que las mayorías no podrán decidir; y después, por cierto, habrá que seguir tomando decisiones sobre la delimitación exacta de los confines sólo genéricamente establecidos a lo que pueden decidir.

A possibilidade de compreensão do funcionamento dinâmico da regra da maioria como regra de decisão coletiva que implique ser autocompreensiva ou aberta significa aceitar que as decisões coletivas devem ser adotadas pela maioria ou por qualquer outro procedimento que o substitua, procedimento este que 
pode ser perfeitamente a abdicação do poder democrático pelo próprio povo em prol de um grupo totalitário ou de alguém.

A questão, longe de estar completamente respondida, permite a ilação de que o coto vedado é um ideal moral de limite, servindo como um pré-compromisso de intangibilidade do procedimento que determina serem as decisões tomadas de forma democrática, respeitando o dualismo democrático que busca - pela ideia de pré-compromisso - uma reconciliação profunda entre a primazia constitucional e a regra de decisão pela maioria (Bayon, 2010, p. 79).

Resta acreditar que a estratégia de Ulisses ${ }^{14}$ funcione, em especial como forma de assegurar a racionalidade do povo de maneira indireta, consistente em impedir de antemão certas opções para se proteger da tendência previsível a adotar decisões que frustrarão o verdadeiro interesse fundamental duradouro e soberano: o poder de determinar contínua e democraticamente suas decisões.

\section{REFERÊNCIAS}

ALEXY, Robert. Teoria dos direitos fundamentais. Trad. Virgílio Afonso da Silva. São Paulo: Malheiros, 2008.

BASTOS, Celso Ribeiro; VARGAS, Alexis Galiás de Souza. Argüição de descumprimento de preceito fundamental. Revista Consulex, 44(2000): 36-37.

BAYON, Juan Carlos. Derechos, Democracia y Constitucion. Redação inédita apresentada em 26 de agosto de 1996 na Universidade de Palermo. Buenos Aires, Argentina. Disponível em: <http://www.Iluisvives.com/servlet/SirveObras/ hist/12925071916700495109213/discusiones1/Vol1_05.pdf>. Acesso em: 15 jul. 2011.

BENEVIDES, Maria Victoria de Mesquita. A cidadania ativa: referendo, plebiscito e iniciativa popular. 3. ed. São Paulo: Ática, 2003.

BOBBIO, Norberto; MATTEUCCI, Nicola; PASQUINO, Gianfranco. Dicionário de política. Trad. Carmen C. Varriale et al. 5. ed. Brasília: Editora Universidade de Brasília, 2000.

BONAVIDES, Paulo. Política e Constituição: os caminhos da democracia. Rio de Janeiro: Forense, 1985.

BRASIL. Constituição da República Federativa do Brasil de 1988. Diário Oficial da República Federativa do Brasil, Brasília, DF, 5 out. 1988. Disponível em: www.planalto. gov.br. Acesso em: 15 jul. 2010.

BUSTAMANTE, Thomas da Rosa de. Argüição de descumprimento de preceito fundamental e sua regulamentação. Jus Navigandi, Teresina, a. 5, n. 40, 1 mar. 2000. Disponível em: <http://jus.uol.com.br/revista/texto/238>. Acesso em: 5 fev. 2011.

CANOTILHO, José Joaquim Gomes. Direito constitucional e teoria da Constituição. 7. ed. Coimbra: Almedina, 2003.

14 Ulisses, personagem de Homero no livro A Odisséia, prendeu-se no mastro de seu barco, porque sabia da irresistível atração do canto das sereias e queria evitar, de antemão, a possibilidade de deixar-se influenciar, o que acarretaria consequências fatais. 
. Da "liberdade dos Amigos" à "liberdade dos Modernos" na teoria republicana dos direitos fundamentais. Estudos sobre Direitos Fundamentais, Lisboa: Coimbra, 2004b.

. Tomemos a sério os direitos econômicos, sociais e culturais. Estudos sobre direitos Fundamentais, Lisboa: Coimbra, 2004a.

DAHL, Robert A. Sobre a democracia. Trad. Beatriz Sidou. Brasília: Editora Universidade de Brasília, 2001.

DALLARI, Dalmo de Abreu. Elementos de teoria geral do estado. 24. ed. São Paulo: Saraiva, 2003.

DWORKIN, Ronald. O império do direito. São Paulo: Martins Fontes, 2003.

ELY, John Hart. Democracia e desconfiança: uma teoria do controle judicial de constitucionalidade. Trad. Juliana Lemos. São Paulo: Editora WMF Martins Fontes, 2010.

FERRAZ JÚNIOR, Tércio Sampaio. Constituinte: assembléia, processo e poder. São Paulo: Revista dos Tribunais, 1985.

FRANCISCO, José Carlos. Emendas constitucionais e limites flexíveis. Rio de Janeiro: Forense, 2003.

HÄBERLE, Peter. Hermenêutica constitucional - A sociedade aberta dos intérpretes da Constituição: contribuição para a interpretação pluralista e "procedimental" da constituição. Trad. Gilmar Ferreira Mendes. Porto Alegre: Sergio Antonio Fabris, 1997.

HABERMAS, Jürgen. Direito e democracia: entre facticidade e validade. 2. ed. Rio de Janeiro: Editora Tempo Brasileiro, v. 1, 2003.

HESSE, Konrad. A força normativa da Constituição. Porto Alegre: Sergio Antonio Fabris, 1991.

HORTA, Raul Machado. Direito constitucional. 2. ed. Belo Horizonte: Del Rey, 1999.

LIJPHART, Arend. Modelos de democracia: desempenho e padrões de governo em 36 países. Trad. Roberto Franco. Rio de Janeiro: Civilização Brasileira, 2003.

LOEWENSTEIN, Karl. Teoria de la Constitución. Trad. Alfredo Gallego Anabitarte.

2. ed. Barcelona: Ariel, 1970.

MANGABEIRA, João. Idéias políticas. Senado Federal/Fundação Casa de Rui Barbosa MEC, Brasília, 1980, v. 3.

MELO, Carlos Antônio de Almeida. Alguns apontamentos sobre a argüição de descumprimento de preceito fundamental. Revista de Informação Legislativa, 145 (2000): 113-118.

MIRANDA, Jorge. Teoria do Estado e da Constituição. Rio de Janeiro: Forense, 2005.

MÜLLER, Friedrich. Quem é o povo? A questão fundamental da democracia. Trad. Peter Naumann. 4. ed. São Paulo: RT, 2009.

POPPER, Karl. A lógica da pesquisa científica. São Paulo: Cultrix, 1974.

QUEIROZ, Cristina. Direitos fundamentais sociais: funções, âmbito, conteúdo, questões interpretativas e problemas de justiciabilidade. Lisboa: Coimbra, 2006.

RAWLS, John. Uma teoria da justiça. Trad. Jussara Simões. 3. ed. São Paulo: Martins Fontes, 2008.

SANTOS, Boaventura de Souza (Org.). Democratizar a democracia: os caminhos da democracia participativa. 2. ed. Rio de Janeiro: Civilização Brasileira, 2003. 
SARLET, Ingo Wolfgang. A eficácia dos direitos fundamentais: uma teoria geral dos direitos fundamentais na perspectiva constitucional. 10. ed. Porto Alegre: Livraria do Advogado, 2009.

SILVA, José Afonso da. Curso de direito constitucional positivo. 26. ed. São Paulo: Malheiros, 2006.

. Poder constituinte e poder popular. São Paulo: Malheiros, 2000.

STRECK, Lênio Luiz; MORAIS, José Luis Bolzan. Ciência política e teoria geral do estado. 4. ed. Porto Alegre: Livraria do Advogado, 2004.

STRECK, Lênio Luiz. Constituição: Limites e perspectivas da revisão. Porto Alegre: Rigel, 1993.

TAVARES, André Ramos. Tratado da argüição de preceito fundamental: Lei no 9.868/1999 e Lei no 9.882/1999. São Paulo: Saraiva, 2001.

TOURAINE, Alain. Crítica da modernidade. Petrópolis, 1994.

VILHENA, Oscar Vieira. Direitos fundamentais: uma leitura da jurisprudência do STF. São Paulo: Malheiros, 2006.

WALDRON, Jeremy. A dignidade da legislação. Trad. Luís Carlos Borges. São Paulo: Martins Fontes, 2003.

WEBER, Max. EConomia e sociedade: fundamentos da sociologia compreensiva. Tradução de Régis Barbosa e Karen Elsabe Barbosa. 4. ed. São Paulo: Imprensa Oficial do Estado de São Paulo, v. 2, 2004. 